\title{
VATS versus open thoracic surgery in Brazil-where are we standing?
}

\author{
Maria Teresa Ruiz Tsukazan ${ }^{1,2}$, Ricardo Mingarini Terra ${ }^{3}$ \\ ${ }^{1}$ Thoracic Surgery Division, Hospital São Lucas Pontifícia Universidade Católica do Rio Grande do Sul, Porto Alegre, Brazil; ${ }^{2}$ Pulmonary and \\ Thoracic Surgery Division, Hospital Moinhos de Vento, Porto Alegre, Brazil; ${ }^{3}$ Thoracic Surgery Division, Universidade de São Paulo, Faculdade de \\ Medicina, Hospital das Clinicas, Instituto do Coração, São Paulo, Brazil \\ Correspondence to: Maria Teresa Ruiz Tsukazan. Av. Ipiranga 6690. Centro Clínico conjunto 615. Jardim Botânico CEP 90610-000, Porto Alegre, RS. \\ Brazil. Email: mtrtsukazan@gmail.com.
}

\begin{abstract}
Video-assisted thoracoscopic surgery (VATS) technique for anatomical lung resections have been available for more than two decades. It's been proved to be a safe technique with lower complications rate and comparable survival outcomes for lung cancer when compared to traditional open thoracotomy. However, this minimally invasive approach is not worldwide widely used. This perspective reviews Brazilian VATS experience.
\end{abstract}

Keywords: Video-assisted thoracoscopic surgery (VATS); lobectomy; lung cancer; lung

Received: 06 August 2018; Accepted: 05 December 2018; Published: 20 December 2018.

doi: $10.21037 /$ jovs.2018.12.02

View this article at: http://dx.doi.org/10.21037/jovs.2018.12.02

\section{Introduction}

Video-assisted thoracoscopic surgery (VATS) for anatomical lung resections have been increasingly performed worldwide for lung cancer with excellent results over more than two decades (1). Several studies have showed VATS technique offers advantages over traditional open thoracotomy. Operative trauma is lower with decreased postoperative pain, less complications and faster recovery. Despite the benefits, the minimally invasive procedure is not performed for the majority of eligible patients according to European Society of Thoracic Surgeons (ESTS) and Society of Thoracic Surgeons (STS) database $(2,3)$.

Emerging countries have a high burden of infection diseases, limited healthcare resources and a diverse ethnic background of patients specially in Latin America. Few information is available regarding VATS lung anatomical resection disease indication and outcomes in this type of setting.

\section{Brazil panorama}

Brazil is a large country with more than 200 million population and approximately 600 thoracic surgeons according to Brazilian Society of Thoracic Surgeons (BSTS). Healthcare system is divided in public (available for everybody) and private (health insurance covering $25 \%$ of population). Public healthcare system does not cover VATS lung resection equipment in all regions. The widespread use of VATS technique in the country happen only 10 years ago. Nevertheless, VATS lobectomy is performed in many centers. BSTS commissioned the first multicenter VATS lobectomy study in Brazil (4). This was a retrospective data analysis where 14 thoracic surgery participated. Outcome results included surgeons learning curve and were comparable to ESTS and STS outcomes.

\section{Training}

Different strategies were adopted in the initial Brazilian experience. First, all surgeons were familiar and had a consolidated experience in minor VATS procedures as wedges, decortications and pleural biopsies. This allowed experience with port placement and instruments usage. Most of mid-level and senior surgeons that wanted to 
migrate to VATS lobectomy chosen to attend specific courses to learn the techniques and visit centers with high VATS lobectomies volume. Younger surgeons tended to do a formal training (fellowship) in North America or Europe after their residence in Brazil. Irrespective of the type of preparation, the centers were able to start a safe VATS lung resection program as seen in first study outcomes (4).

Nowadays, VATS lung resection is better established and incorporated in most residencies programs. However, the training is very heterogenous across the country (academic, public or private setting). In order to reinforce VATS techniques foundation, BSTS has an annual handson course that all thoracic surgery residents are invited to participate. This is great not only for theorical and handson purposes but also a great opportunity to share experience and stablish a good network and bring them close to SBCT.

\section{VATS versus thoracotomy}

BSTS database was launched in 2015 using the ESTS platform. That was an important step that allowed a more detailed analysis of lung resections procedures. Until February 2018, 5,570 patients were registered in BSTS database and 1,663 had anatomical lung resection. Interesting, $45.2 \%$ were performed by VATS.

Recently a propensity score-matching comparing VATS to open thoracotomy was published (5). Both benign and lung cancer were included in the study in order to answer the question according to our reality. Before matching there were 1,355 lung resections, 651 (48\%) were VATS and $805(59.4 \%)$ had cancer for diagnosis. The outcomes were similar to other studies regarding morbidity and mortality $(2,3,5-10)$. Overall $21.8 \%$ versus $30.1 \%(P=0.002)$ and major complications $9.2 \%$ versus $16 \%(\mathrm{P}=0.002)$ for VATS and thoracotomy, respectively, favors minimally invasive approach. Subgroup analysis for patients ASA >2, cancer or benign diagnosis also significantly favors VATS over thoracotomy (5).

Anatomical lung resection for benign disease tend to have dense pulmonary adhesion, neovascularization and enlarged and adherent lymph nodes. We would think those characteristics frequently present in bronchiectasis, lung sequestration and tuberculosis would lead to more complications as prolonged air-leak and hemothorax. Weber and Kim showed outcomes for VATS versus open thoracotomy for benign disease were comparable $(11,12)$. In our propensity score-matching analysis VATS had lower overall complications compared to open thoracotomy.

\section{Perspectives}

Brazil is a country of continental dimensions with a very heterogeneous population and VATS has only come into widespread use in the country over the last ten years. Irrespective of mixed cases (benign and cancer), studies in Brazil strongly support the wider adoption of VATS, particularly for high-risk patients, for whom it provides particularly important benefits. These results are also generalizable to other emerging countries, especially those in Latin America, which share many of the same structural and demographic characteristics as Brazil. We hope to have soon a more homogenous access to this technique, especially for high-risk patients which most benefit from this approach.

\section{Acknowledgments}

Funding: None.

\section{Footnote}

Provenance and Peer Review: This article was commissioned by the editorial office, Fournal of Visualized Surgery for the series "Minimally Invasive Surgery - Robotics and VATS in Brazil". The article has undergone external peer review.

Conflicts of Interest: The series "Minimally Invasive Surgery Robotics and VATS in Brazil" was commissioned by the editorial office without any funding or sponsorship. RMT served as the unpaid Guest Editor of the series and is in the Advisory Board of Johnson \& Johnson and Medtronic. Educational activities for $\mathrm{H}$. Strattner/Intuitive. The authors have no other conflicts of interest to declare.

Ethical Statement: The authors are accountable for all aspects of the work in ensuring that questions related to the accuracy or integrity of any part of the work are appropriately investigated and resolved.

Open Access Statement: This is an Open Access article distributed in accordance with the Creative Commons Attribution-NonCommercial-NoDerivs 4.0 International License (CC BY-NC-ND 4.0), which permits the noncommercial replication and distribution of the article with the strict proviso that no changes or edits are made and the original work is properly cited (including links to both the formal publication through the relevant DOI and the license). 
See: https://creativecommons.org/licenses/by-nc-nd/4.0/.

\section{References}

1. Kirby TJ, Mack MJ, Landreneau RJ, et al. Initial experience with video-assisted thoracoscopic lobectomy. Ann Thorac Surg 1993;56:1248-52; discussion 1252-3.

2. Falcoz PE, Puyraveau M, Thomas PA, et al. Video-assisted thoracoscopic surgery versus open lobectomy for primary non-small-cell lung cancer: a propensity-matched analysis of outcome from the European Society of Thoracic Surgeon database. Eur J Cardiothorac Surg 2016;49:602-9.

3. Paul S, Altorki NK, Sheng S, et al. Thoracoscopic lobectomy is associated with lower morbidity than open lobectomy: A propensity-matched analysis from the STS database. J Thorac Cardiovasc Surg 2010;139:366-78.

4. Terra RM, Kazantzis T, Pinto-Filho DR, et al. Anatomic pulmonary resection by video-assisted thoracoscopy: the Brazilian experience (VATS Brazil study). J Bras Pneumol 2016;42:215-21.

5. Tsukazan MTR, Terra RM, Vigo A, et al. Video-assisted thoracoscopic surgery yields better outcomes than thoracotomy for anatomic lung resection in Brazil: a propensity score-matching analysis using the Brazilian Society of Thoracic Surgery database. Eur J Cardiothorac Surg 2018;53:993-8.

6. Kirby TJ, Mack MJ, Landreneau RJ, et al. Lobectomy

doi: 10.21037/jovs.2018.12.02

Cite this article as: Tsukazan MT, Terra RM. VATS versus open thoracic surgery in Brazil-where are we standing? J Vis Surg 2018;4:249. video-assisted thoracoscopic surgery versus muscle-sparing thoracotomy: A randomized trial. J Thorac Cardiovasc Surg 1995;109:997- 1001; discussion 1001-2.

7. Ceppa DP, Kosinski AS, Berry MF, et al. Thoracoscopic Lobectomy Has Increasing Benefit in Patients With Poor Pulmonary Function: A Society of Thoracic Surgeons Database Analysis Ann Thorac Surg 2012;256:487-93.

8. Laursen LØ, Petersen RH, Hansen HJ, et al. Videoassisted thoracoscopic surgery lobectomy for lung cancer is associated with a lower 30-day morbidity compared with lobectomy by thoracotomy. Eur J Cardiothorac Surg 2016;49:870-5.

9. McKenna RJ Jr, Houck W, Fuller CB. Video-assisted thoracoscopic surgery Lobectomy: Experience With 1,100 Cases. Ann Thorac Surg 2006;81:421- 5; discussion 425-6.

10. Swanson SJ, Meyers BF, Gunnarsson CL, et al. VideoAssisted Thoracoscopic Lobectomy Is Less Costly and Morbid Than Open Lobectomy: A Retrospective Multiinstitutional Database Analysis. Ann Thorac Surg 2012;93:1027-32.

11. Weber A, Stammberger U, Inci I, et al. Thoracoscopic lobectomy for benign disease--a single centre study on 64 cases. Eur J Cardiothorac Surg 2001;20:443-8.

12. Kim D, Kim HK, Choi YS, et al. Is video-assisted thoracic surgery lobectomy in benign disease practical and effective? J Thorac Dis 2014;6:1225-9. 